\section{P53 CHEST PAIN IN CHILDREN: COMMON SYMPTOM THAT MAY CONCEAL ORGANIC HEART DISEASE}

${ }^{1}$ Agori-Dimitra Lasda*, ${ }^{2}$ Evaggelia Kolofotia. ' General Hospital of Karystos, Karystos- Evoia, Greece; ${ }^{2}$ Pediatric Hospital 'Agia Sofia', Athens, Greece

10.1136/archdischild-2019-epa.408

Introduction Chest pain is a common symptom in the pediatric population which, contrary to the adults, occurs usually at rest but may conceal severe organic disease. This study prospectively evaluated clinical characteristics and causes of chest pain in children presenting in the emergency department with this chief complaint.

Methods The study included children with chest pain evaluated in the emergency department of a district hospital during the last 2 years. Associated symptoms, family history, physical examination findings, electrocardiogram and laboratory workup (complete blood count, biochemical values and cardiac enzymes where indicated) and electrocardiogram were recorded in all patients.

Results A total of 52 patients (age 4.5-14 yrs, 29 boys) were evaluated. Chest pain was $94 \%$ at rest and mostly (73\%) acute. Chest pain was found to be idiopathic in $46 \%$ and associated with organic causes in the remainder, in whom heart disease was relatively rare at $8 \%$, while association with the musculoskeletal system was found in $12 \%$, the respiratory system in $11 \%$ and the gastrointestinal system in $8 \%$ of patients. Patients with a history of psychological issues (8\%) were evaluated by a child psychiatrist. Laboratory tests were deemed necessary in $40.6 \%$ of patients with only 8 patients (15\%) having results related to the organic background of chest pain. Electrocardiogram was normal in 43 children $(82.7 \%)$, with 9 patients $(17.3 \%)$ showing non-specific abnormalities, such as $\mathrm{RBBB}$, negative $\mathrm{T}$ in $\mathrm{V} 1-\mathrm{V} 3$ and respiratory arrhythmia. Echocardiogram by the adult cardiologists was requested in 24 patients (46\%), while 14 patients (27\%) were referred for paediatric cardiology evaluation. Only 2 patients $(3.8 \%)$ in this cohort were found to have previously unknown cardiac disease possibly related to the chest pain, myocarditis in one and pulmonary stenosis in a second patient.

Conclusions Chest pain in the paediatric population is mostly idiopathic or associated with noncardiac disorders, but may also be a symptom of serious heart disease that should not be missed. Paediatric history, physical examination, laboratory testing and electrocardiogram can usually diagnose organic causes and paedocardiologic assessment should be recommended in suspicious cases and not used just for reassurance of the primary care physician.

\section{P54 INCIDENCE AND SPECTRUM OF CONGENITAL HEART DEFECTS AMONG NEONATES IN THE TERTIARY CARE CENTRE OF YAKUTIA}

\begin{abstract}
${ }^{1}$ Tuyara Nelunova, ${ }^{2,3}$ Tatiana Burtseva, ${ }^{1}$ Sergei Avrusin, ${ }^{1}$ Elena Sinelnikova*, ${ }^{1}$ Irina Solodkova, ${ }^{1}$ Tatiana Kornishina, ${ }^{1}$ Vera Masalova, ${ }^{1}$ Tatiana Likhacheva, ${ }^{1}$ llia Avrusin, ${ }^{1}$ Vyacheslav Chasnyk. 'Saint-Petersburg State Pediatric Medical University, Saint-Petersburg, Russian Federation; ${ }^{2}$ M.K.Ammosov North-Eastern Federal University, Yakutsk, Russian Federation; ${ }^{3}$ Yakutia Science Center for Complex Medical Problems of the Russian Academy of Sciences, Yakutsk, Russian Federation
\end{abstract}

10.1136/archdischild-2019-epa.409

Introduction Congenital heart disease (CHD) is the largest class of all major congenital anomalies. It occurs in $0.6-1 \%$ of live births throughout the world. The prevalence of specific defects is known to be associated with race/ethnicity. Asian children are reported to be at higher risk of complex $\mathrm{CHDs}$ than non-Asians. Various factors were supposed to be the cause of higher CHD prevalence in individual ethnic groups with genetic, lifestyle, socioeconomic, ecological factors and restricted access to health services being among them. The goal of this study was to reveal the dynamics of incidence and spectrum of CHDs among neonates of different ethnic groups delivered in the tertiary care center of Yakutia in 2001 - 2013.

Methods Spectrum of CHD among neonates examined in the Yakutsk Diagnostic Centre was analyzed retrospectively. Eligibility criteria for the detailed medical evaluation: a CHD in family history or any clinical sign of CHD. Neonates, suspected of having CHD, were further evaluated by pulse oximetry, chest X-ray and echocardiography to ascertain the diagnosis. Information regarding gender, mode of delivery, gestational age, body weight and length at birth, socioeconomic status of the family, family history, ethnicity and place of residence of 724 and 1226 babies, who were examined in 2001 - 2003 and in 2011 - 2013 respectively, were processed using the SPSS-16 package.

Results Of all babies, eligible for the detailed evaluation in both periods, ventricular septal defect was revealed in $6.4 \%$, atrial septal defect - in 4.6\%, patent ductus arteriosus - in $2.6 \%$, tetralogy of Fallot - in 1.4\%, coarctation of the aorta - in $0.9 \%$, pulmonary atresia - in $0.7 \%$ ), complete atrioventricular canal - in $0.5 \%$ and Ebstein's anomaly - in $0.5 \%$. Comparison of CHD incidence and patterns in 2001 - 2003 and in 2011 - 2013 revealed an almost 2fold increase in the total number of CHD $(p<0.01)$. Ratio of simple CHD increased from $22.4 \%$ to $39.9 \% \quad(p<0.03)$ and ratio of complex CHD - from $3 \%$ to $8.2 \%(\mathrm{p}<0.02)$. Data mining didn't reveal associations between the incidence of CHD and indices of socioeconomic status but identified associations with ethnicity and place of residence $(\mathrm{p}<0.05)$.

Conclusions Revealed higher incidence of CHD is due to the fact that the study was carried out in a tertiary care unit, which is the only referral hospital in Yakutia. Increased number of CHD reflects rather better availability of cardiac services and higher professional qualification of specialists than a higher incidence of CHD in 2011 - 2013.

\section{P55 A CASE OF VEIN OF GALEN MALFORMATION WITH ATRIOVENTRICULAR SEPTAL DEFECT}

Muhammad Shoaib Iqbal* , Sanjay Raina. Princess Alexandra Hospital, Harlow, UK

\subsection{6/archdischild-2019-epa.410}

Background Vein of galen, is a cause of congestive cardiac failure. It can be difficult to diagnose as the clinical picture can mimic the congenital heart defects. Neonates and young infants with vein of galen can present with intractable heart failure.

Objectives Vein of galen can present with features of congestive heart failure. Presence of congenital heart defect can make it difficult to diagnose. Thorough physical examination can help in early diagnosis.

Methods Patient history and examination retrieved from the patient notes and images retrieved from the system. 


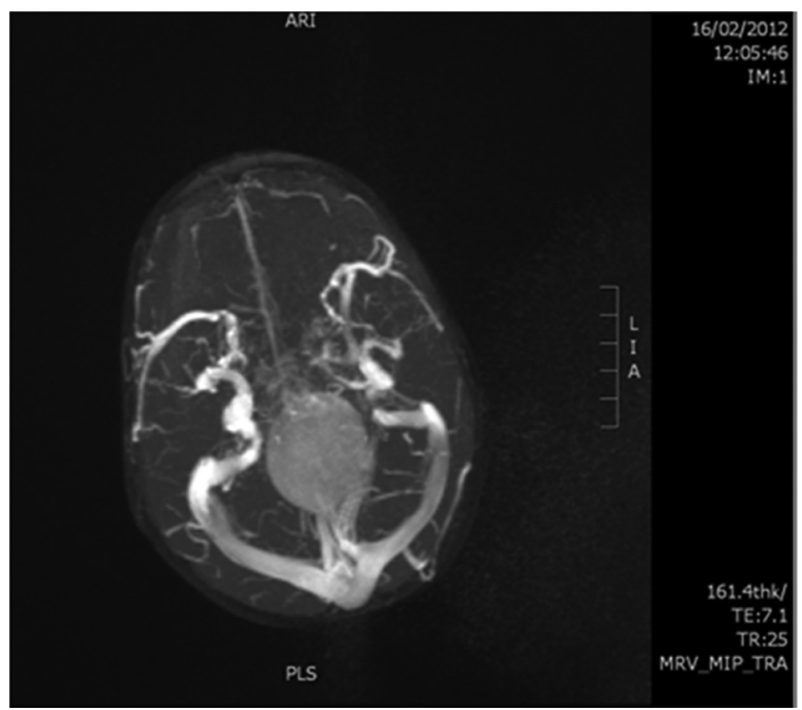

Abstract P55 Figure 1

Results 5 months old child with atrial septal defect with partial anomalous pulmonary venous drainage was seen in cardiology clinic and based on failure to thrive with congenital heart defects and respiratory distress, he was admitted to the paediatric ward with the impression of heart failure. As there was congenital heart defect so the heart failure was thought to be from the congenital heart defect and it was difficult to manage as well. Later on, examination picked up a cranial bruit, MRI brain showed vein of galen malformation. Child was transferred to tertiary neurosurgery and glue embolization was performed which was uneventful.

Conclusion This case illustrates the presentation of vein of galen with heart failure in a child with congenital heart defects. There was cardiac defect so that was thought to be the cause of heart failure but later on examination picked up cranial bruit and MRI brain confirmed the vein of galen malformation.

\section{P56 OBESITY AND ACCOMPANYING RISK FACTORS IMPORTANT FOR THE ONSET OF ATEROSCELLOSIS}

Gordana, Milorad Grujic Ilic, Jerkan*, Milorad Jerkan. Health Center Nis, Nis, Serbia

10.1136/archdischild-2019-epa.411

Obesity is one of the significant risk factors in the development of atherosclerosis, the most common metabolic disorder which the world's health organization classified as an epidemic disease.

Aim Point to frequency of obesity in children, risk factors significant for the onset of atherosclerosis in obese children and association of these factors.

Methods 2069 children aged 2-19 were examined. Body mass index (BMI) (Body weight/Body height $\left.{ }^{2}\right)\left(\mathrm{kg} / \mathrm{m}^{2}\right)$ was calculated. Tables of international standards for BMI of children corresponding to BMI in adults were used for the assessment of nutrition. Obesity is classified with BMI> 30 $\mathrm{kg} / \mathrm{m}^{2}$. Blood pressure $(\mathrm{BP} / \mathrm{mmHg})$, systolic and diastolic was measured. Total cholesterol (TC), high density lipoprotein cholesterol (HDL-C), triglycerides (TG) concentrations were determined. Low density lipoprotein (LDL-C), nonHDL cholesterol (TC-HDL-C) were calculated. 2016 ESC/EAS guidelines for the management and European guidelines for prevention, diagnosis and treatment of high BP in children and adolescents (2010) were used to estimate the results.

Results There were $10.45 \%$ obese and $15.6 \%$ overweight children. BP (Systolic, Diastolic) were significantly higher in obese $(105.71 / 65.82)$ than in normal weight children (94/58.79). In the obese there was a really significant connection between BMI and BP, Systilic $(r=0.625)$ and diastolic $(r=0.541)$. TC, LDL-C, TG and nonHDL-C values were significantly higher in obese $(4.25 ; 2.53 ; 1.13 ; 3.02$ $\mathrm{mmol} / \mathrm{l})$ than in normal weight $(4.06 ; 2.31 ; 0.92 ; 2.73$ $\mathrm{mmol} / \mathrm{l})$. HDL-C values were significantly lower $(<0.001)$. The percentage of children with increased values of SBP, DBP, and SBP and DBP was higher in obese children $(15.35 \% ; 6.64 \%$ : $5.81 \%)$ than in normal weight $(1.26 \%$; $1.08 \% ; 0.42 \%)$.

The percentage of children with lipid and lipoprotein values which are a high risk factor for the development of cardiovascular diseases in adulthood was higher in obese children and also was the percentage of children with more associated values.

Conclusion Blood pressure values, lipids and lipoproteins values, which are significant risk factors for the onset of atherosclerosis, were higher in obese children. It is necessary to detect obese children on time and apply all preventive measures in its control and elimination. The chosen doctor plays a major role in this. It is necessary to have continuous parents and teachers education about proper children diet and the role of physical activity, smoking and alcoholism prevention. The whole community should also be involved.

\section{P57 PATHOGENETIC VALUE OF ENDOTHELININ IN PREDICTING THE CLINICAL COURSE OF CARDIOMYOPATHY IN CHILDREN}

1,2Dilorom Akhmedova*, ${ }^{2}$ Nilufar Akhmedova, ${ }^{1}$ Alima Matkarimova. ${ }^{1}$ Republican Specialized Scientific and Practical Medical Center of Pediatrics, Tashkent, Uzbekistan; ${ }^{2}$ Tashkent Pediatric Medical Institute, Tashkent, Uzbekistan

\subsection{6/archdischild-2019-epa.412}

Relevance The study of biochemical changes in cardiovascular diseases is one of the urgent problems of pediatric cardiology. Biochemical markers of myocardial damage include cardiospecific proteins - troponin, endothelin and myoglobin, which provide some assistance in specifying an unfavorable cardiomyopathic prognosis.

Purpose of the study To study the pathogenetic significance of endothelin in predicting the clinical course of cardiomyopathy in children.

Materials and methods 54 children with diagnoses of dilated and hypertrophic cardiomyopathy were hospitalized in cardioreumatology departments of the Republican Specialized Scientific and Practical Medical Center of Pediatrics in Tashkent and the Republican Children's Multidisciplinary Medical Center in Nukus. The age of the examined children ranged from 1 year to 17 years and averaged $7.1 \pm 0.7$ years. Biochemical methods included the determination of endothelin in the serum by immunofluorescence analysis on an IMAXIZ 